\title{
FUNCIONAMENTO DE FAMÍLIAS COM MEMBROS DEPENDENTES DE SUBSTÂNCIAS PSICOATIVAS
}

\author{
The functioning of families with psychoactive substanoes addicted members
}

\author{
Anaídes Pimentel da Silva Ortha, Carmen Leontina Ojeda Ocampo Moré ${ }^{\mathrm{b}}$ \\ a Psicóloga Clínica, Hospitalar e Institucional, mestre em Psicologiapela Universidade Federal de Santa Catarina, Curitiba, PR - \\ Brasil, e-mail: anaidespso@yahoo.com.br \\ ${ }^{\text {b }}$ D ra. em Psicologia Clínica, professora da G raduação e Pós-G raduação do D epartamento de Psicologia da Universidade Federal \\ de Santa Catarina, Florianópolis, SC - Brasil, e-mail: cmore@ mbox1.ufsc.br
}

\begin{abstract}
Resumo
O objetivo do presente estudo foi caracterizar aspectos da estrutura e dinâmica das famílias com um ou mais membros que estabelecem uma relação de dependência com substâncias psicoativas. Buscouse somar subsídios para uma melhor compreensão do cenário familiar, na busca de estratégias eficazes de enfrentamento da temática da drogadição, tanto pela família, como pelos profissionais de saúde. Tendo como base os parâmetros da pesquisa qualitativa, foram realizadas entrevistas semiestruturadas que subsidiaram a construção do genograma trigeracional de seis famílias participantes deste estudo. O s dados obtidos foram submetidos à análise de conteúdo, sendo, após, organizados em categorias temáticas. O s resultados evidenciaram que tanto a estrutura, em termos de organização familiar, e dinâmica relacional estavam sustentadas por: a) presença do modelo adicto tanto pelos pais, como em membros das gerações anteriores; b) instabilidade familiar, no sentido da fragilidade de apoio da família para seus membros; c) evolução do uso precoce de droga pelo indivíduo; d) carência de vínculos familiares, escolares e comunitários. O bservou-se que as famílias aparecem como "coautoras" tanto do surgimento do abuso da droga e de sua evolução, bem como na busca de recursos para tratamento dos membros usuários. D estaca-se a importância da perspectiva intergeracional para ampliar a compreensão e o leque de possibilidades de intervenção nessa temática complexa.
\end{abstract}

Palavras-chave: D ependência química; Estrutura e dinâmica familiar; Transgeracionalidade. 


\begin{abstract}
The objective of the present study was to characterize the aspects concerning the structure and dynamic of families with psychoactive substances addicted members. There was an effort to sum resources for a better comprehension of the family setting through the constant search for efficient strategies to deal with this theme by both family and health professionals. The research was based on the descriptive qualitative method, consisting in semi structured interviews which subsidized the creation of a genogram over three generations of the six families that participated in the research. The collected data were analyzed and as a result organized and grouped in categories. The results suggest that not only the structure, in terms of family organization, but also the dynamics related to it were sustained by: a) parental and previous generation drug use model; b) family instability, meaning fragility of the support given to it by its members c) beginning and evolution of the precocious drug use; $d$ ) lack of school and community ties. It was also observed that the families are co-authors as for the emergence and evolution of the drug abuse as for the search of treatment to their members. As a whole, the study of genealogy is emphasized as a tool to increase understanding and the number of interventions possible in such a complex thematic.
\end{abstract}

Keywords: Chemical dependency; Family dynamics and structure; Transgeneration.

\section{INTRODUÇÃO}

A temática da drogadição e sua relação com o homem acompanham a história da humanidade ao longo dos tempos, passando lentamente de um uso ritualístico, com finalidade detranscendência na antiguidade, para o consumo contemporâneo de busca de prazer, alívio imediato de desconforto físico, psíquico ou de pressão social, estando presente em todas as classes sociais.

A drogadição se expressa no indivíduo através da conduta adicta que, por sua vez, sustenta 0 processo da dependência química, constituindo um circuito que se retroalimenta constantemente e que está presente, seja na presença de drogas lícitas ou socialmente aceitas, ou ilícitas. Esse circuito, uma vez estabelecido, afeta diretamente as relações interpessoais, sendo a família o primeiro e principal sistema, onde se observam as consequências, tanto na saúde de seus membros, como na extrema fragilização das relações familiares.

Em termos sociais, a drogadição evidencia uma trama constituída pelas interfaces de diferentes sistemas envolvidos diretamente no processo da dependência química, tais como: a interação entre 0 drogadicto e a droga; 0 drogadicto e a família; drogadicto e a polícia; drogadicto e o tráfico, o que revela sua complexidade, tanto em termos de análises, como de estratégias de ação.
O s estudos - como os de Stanton e Todd (1985), Carter e McGoldrick (2001), e Kalina (1999) - para compreender, conceituar e prevenir a multifatoriedade de aspectos que permeiam a drogadição conjugam a ideia de que é o conjunto dos fatores biopsicossociais que interferem direta e indiretamente no processo da dependência química, afetando-se mutuamente, constituindo-se, assim, num fenômeno complexo, em que vários elementos de análises convergem, tanto para seu surgimento, como para sua sustentação, sendo a família um dos sistemas que maior atenção requer nesse processo, por se constituir numa das principais fontes de proteção e risco nos estágios de desenvolvimento psicológico do indivíduo.

Assim, visando somar subsídios para melhor compreensão do cenário familiar, na busca por melhores estratégias de enfrentamento da temática da drogadição, tanto pela família, como dos profissionais de saúde que atuam nos diferentes níveis de atenção à saúde, seja na atenção primária, seja em programas de atendimento dessas demandas ou em sua atividade clínica, o objetivo do presente estudo foi o de caracterizar aspectos da estrutura e dinâmica das famílias com um ou mais membros que estabelecem uma relação de dependência com substâncias psicoativas. 


\section{A família e a dependência química}

Entende-se a família como um sistema aberto, no sentido de suas trocas com o meio, cujos membros têm contato direto, laços emocionais e uma história compartilhada. Apresenta uma estrutura com a presença de padrões e propriedades que organizam a estabilidade da família em termos de sustentar uma dinâmica relacional que contemple os fatores de proteção necessários para seu desenvolvimento enquanto grupo e indivíduos, convivendo com os desafios das mudanças próprias das transições presentes no ciclo vital da família (Minuchin, Colapinto \& Minuchin, 1999).

A ideia de que há influência da família no desenvolvimento da drogadição é constatada na literatura científica e pelos profissionais que a acolhem em suas práticas de intervenção, os quais são desafiados rotineiramente pela complexidade da temática, associando a isso 0 fato de não poder definir a priori apenas um tipo específico de funcionamento familiar.

Nem todas as famílias de dependentes químicos podem ser consideradas não funcionais, no sentido de não ter fatores de proteção necessários para 0 desenvolvimento de todos seus membros. Por sua vez, cabe apontar, no entanto, que em muitas famílias com dependentes, ocorre um processo de circularidade em que a nãofuncionalidade e 0 abuso de drogas reforçam-se mutuamente, mantendo, assim, ahomeostasefamiliar que sustenta a presença desta nas relações familiares.

No que diz respeito ao começo do uso de substâncias psicoativas, a adolescência é apontada pela literatura científica como uma fase do desenvolvimento do indivíduo em que surge como consequência das mudanças decorrentes do ciclo vital individual de transição desenvolvimental, na qual 0 jovem experimenta novas condutas, abandonando um lugar infantil, buscando autoafirmação social através de suainserção em diferentes grupos e começa a ter relações de amizade e íntimas com pessoas que não integram o meio familiar (Figlie \& Moraes, 2004; Freitas, 2002; Subdrack, 2004).

Associado a isso, Stanton e Todd (1985) e Kalina (1999), estudiosos clássicos dessa temática, apontam que há, na adolescência, três tempos: 0 primeiro é o uso do álcool e se manifesta como um fenômeno social; depois vem o uso da maconha, que é influenciado pelos pares; e em terceiro o uso de drogas ilegais. Esse terceiro tempo e seu agravamento estão relacionados mais diretamente à qualidade da relação estabelecida entre os pais e o filho do que a outros fatores. D essa forma, supõese que o uso de drogas mais letais à saúde, que geram quadros de dependência, é consequência de uma disfunção familiar.

No que diz respeito à dinâmica dos relacionamentos na família, estudos mostram que nas famílias com dependentes masculinos, a figura materna mantém um comportamento apegado, superprotetor, permissivo com o dependente, e este ocupa uma posição favorecida em relação aos outros filhos. Asmães dos usuários geralmenteos descrevem como bem educados e afirmam que não deram trabalho. Em compensação, os pais são vistos como ausentes, desapegados e fracos, e por sua vez, com uma disciplina rude e incoerente, e as relações estabelecidas são difíceis, com efetivo distanciamento afetivo (Carter \& McG oldrick, 2001; Cerveny, 1997; Costa \& Pereira, 2003; Freitas, 2002).

Os irmãos dos usuários masculinos mantêm com o pai uma relação mais positiva e próxima. Porém, segundo os autores, esses dados não podem ser generalizados, pois, em algumas famílias, ocorre que, antes da mãe estabelecer uma relação de apego, é o pai quem o faz e se intromete demais nas relações familiares. É comum também encontrar o abuso de álcool pelos pais nessas famílias, que podem ser descritas de dois tipos: uma na qual o pai se apresenta como autoritário e violento, mas é facilmente controlado pela mãe, e outra na qual a mãe tem claramente o poder dentro da família. Já as usuárias do sexo feminino mantêm com a mãe uma relação de rivalidade e as veem como figuras autoritárias e superprotetoras; enquanto que os pais são caracterizados como incapazes, indulgentes, sexualmente agressivos e alcoolistas. Podendo ocorrer nestes casos um risco maior de incesto (Stanton \& Todd, 1985).

Em ambas as famílias, tanto as dos usuários masculinos como as dos femininos, há, na maioria dos casos, ausência de um dos progenitores, frequentemente 0 pai, ou então dos dois, seja por separação ou morte. O início do uso de drogas, segundo Stanton eTodd (1985), pareceestarassociado a esta perda ou então a de outra pessoa significativa, geralmente devido a mortes repentinas e traumáticas.

Nessas famílias, os adictos tendem a estabelecer relações externas (grupos de amigos) fortes eque, em situações de conflito, buscam refúgio nesses amigos, construindo uma falsa ideia de 
independência, que é formada, também, pela relação que essas pessoas mantém com a subcultura na qual estão inseridas. Mesmo assim, as alianças entre os membros familiares são muito fortes e explícitas, sendo que as mães dos dependentes relacionam-se com estes de forma a não haver uma separação entre si, o que torna a relação simbiótica, na qual a mãe se apega ao filho desde a tenra idade e trata-o como se tivesse idade menor do que realmente tem (Kalina, 1999; Stanton \& Todd, 1985; Subdrack, 2004).

Autores como Kaufman (1989) e Rezende (1997) destacam em seus estudos que o drogadicto é o portador do sintoma da disfunção familiar e colaboraparamanterahomeostase desta, reforçando o padrão controlador dos pais, mesmo não sendo tal prática adequada às suas necessidades. Também é comum outros membros da família apresentarem comportamentos adictos, tais como compulsão ao jogo, à comida, ao trabalho, às drogas e outros. Em muitos casos, o comportamento adicto criasituações para desfocalizar o problema de relacionamento dos pais, ou estabelece uma aliança com um dos pais em separado, ou então as fronteiras geracionais (conjugal, parental e fraternal) não estão bem definidas e, frequentemente, existe competição entre os pais e irmãos.

Observa-se, assim, que o problema da dependência química é parte do funcionamento familiar, econtribui paraa estabilidadedesse sistema. A dependência pode aparecer para resolver um conflito que surge no ciclo vital familiar e, consequentemente, faz com que afamíliapermaneça nessa mesma etapa do ciclo vital familiar. Para autores como Kalina (1999); Stanton e Todd (1985); Subdrack (2004); o uso de drogas também traz a angústia encontrada no processo de separação e de distanciamento desta relação familiar. $\mathrm{Na}$ droga, 0 adicto também pode encontrar a sensação de poder e realização pessoal, mesmo que momentânea, que ele não consegue sustentar dentro da família, já que esta necessita de seu fracasso para manter sua aparente estabilidade. Os adictos também se tornam mais agressivos com seus progenitores, numa tentativa de conseguir e manter uma pseudoindependência, já que esses jovens retornam à família depois do uso de drogas. Assim, a família vivencia continuamente a sensação de abandono e de retorno, sendo que esta ambivalência é neutralizada com a justificativa de que o filho estava sob o efeito de drogas no momento em que se tornou agressivo.

Este poder alcançado com o efeito da droga também pode ser alcançado dentro da subcultura da droga, uma vez que 0 adicto pode construirum lugarderespeito dentro desta, àmedida que vai formando amizades e, de certa maneira, se afastando fisicamente de sua família. Porém, 0 usuário só consegue construir esse lugar de êxito dentro de um ambiente de fracassados (Brasil, 2004; Silva, 2001; Stanton \& Todd, 1985).

Estudos de autores já citados demonstram que, em sua maioria, a família de adictos é um exemplo de um sistema de retroalimentação negativa, uma vez que cada indivíduo desse sistema exerce influência no outro, que acaba influenciando um terceiro, que volta a influenciar o primeiro, fechando 0 ciclo que se repete continuamente. A morte do adicto não é capaz de tornar funcional esse ciclo, uma vez que permanecerá presente na dor da família, fazendo com que o casal consiga esconder seus conflitos. Porém, essa resolução não é definitiva, pois o que se percebe é que, passado algum tempo de luto, os conflitos do casal começam a reaparecer, estabelecendo uma nova tríade com um outro filho ou então acaba se separando.

Kaufmann (1989) ressalta que, para os farmacodependentes, a família é um fator crítico no tratamento e sua abordagem é um procedimento fundamental nos programas terapêuticos. Frisando o papel da família na drogadição, estudiosos como Brasil (2004); K alina (1999); Carter e McG oldrick (2001); Silva (2001); Stanton e Todd (1985); têm salientado que dificilmente é possível sustentar a melhora de um paciente sem que atuemos em seu meio familiar, apontando que diferentes estratégias podem ser utilizadas na terapia familiar, desde que sejam considerados os padrões comuns de relacionamento destas famílias e um procedimento para controlar o uso da droga estabelecido.

Em 2001, Galanter afirmava que o problema do abuso de substâncias psicoativas adquiriu crescente prevalência em todo o mundo, 0 que vem estimulando inúmeras propostas de tratamento orientadas especificamente às dependências. De maneira geral, essas propostas abordam o paciente em múltiplos níveis, de forma aincluirnão só o indivíduo dependente, mas também sua família (Brasil, 2004; Silva, 2001). 


\section{MÉTODO}

\section{Participantes e instrumentos da coleta de dados}

Participaram desse estudo seis famílias integrantes do grupo Psicoeducacional, deum Centro de Atenção Psicossocial para usuários de álcool e drogas - CAPSad. De uma cidade do Estado do Paraná. Os critérios utilizados para a adesão das famíliasà pesquisaforam o departicipação voluntária e, ao mesmo tempo, aquelas que atendiam os seguintes critérios: 1) famílias com um ou mais membros dependentes de substâncias psicoativas; 2) famílias de pacientes com mais de um mês de tratamento no CAPSad; 3) famílias de pacientes que possuam idade superior a 18 anos, com diagnóstico de D ependência Química nos critérios do CID 10 (Classificação Internacional de D oenças). Cabe destacar que foi considerado como família, o grupo de pessoas que acompanhava o tratamento do paciente apresentando uma ligação com este através de laços sanguíneos eafetivos, representados por pai, mãe, filhos, irmãos, cônjuges e cunhados.

As famílias pesquisadas constituíam-se de membros com faixa etária entre 20 a 42 anos, pertencentes a classes sociais economicamente desfavorecidas e residentes em bairros de periferia. Quanto ao estado civil, um era casado e três eram amasiados, sendo queum delesamasiou-seporquatro vezes. Q uanto à escolaridade, três cursaram o ensino médio completo, um o ensino médio incompleto e dois o ensino fundamental incompleto. Desse total, cinco tinham profissão; (1 açougueiro, 1 empresário, 2 mecânicos e 1 agente de segurança) e 1 deles definiu-se sem profissão. D e acordo com os relatos, 0 início do uso de drogas aconteceu na préadolescência e adolescência, sendo que três iniciaram com álcool, dois com inalantes, um com maconha e todos evoluíram para outras drogas como: álcool, cigarro, inalantes, maconha, lança-perfume, cocaína e crack. Quando ao aspecto legal, quatro dos participantes tiveram problemas com a justiça. 0 diagnóstico de todos os pacientes era de dependência química, CID F19.2, eencontravam-seem tratamento no CAPSad, sendo que três encontravam-se na modalidade de tratamento intensivo, dois em semiintensivo e um, não intensivo. Q uanto aos membros das famílias que participaram da entrevista, a maioria eram figuras femininas, que corresponderam a
78,57\%, distribuídos em: quatro mães, três irmãs, uma esposa e três companheiras. D a figura masculina participaram dois pais, um cunhado e um enteado, correspondendo a $21,43 \%$.

O s instrumentos de coleta de dados foram: a entrevista semiestruturada e o genograma trigeracional da família. A entrevista semiestruturada subsidiou à construção do genograma familiar, no sentido de manter o foco no interesse da pesquisa $\mathrm{e}$ procurando o sentido particular da experiência. Já 0 genograma familiar representa o mapeamento gráfico da "história e do padrão familiar, mostrando a estrutura básica, a demografia, o funcionamento e os relacionamentos da família", configurando-se como um gráfico sumário dos dados coletados (G erson \& McGoldrick 2001; Carter \& McGoldrick, 2001, p.145). Esse recurso explora os esquemas familiares e explicita a estrutura familiar ao longo de várias gerações e das etapas do ciclo de vida familiar, além dos movimentos emocionais a ele associados. Cabe mencionar que o trabalho de coleta teve início somente após consentimento do comitê de ética das Instituições envolvidas, leitura do consentimento informando atodosos participantes equestionamento do entendimento para esclarecer dúvidas a respeito.

\section{ANÁLISE E DISCUSSÃO DOS RESULTADOS}

A integração dos dados advindos da entrevista semiestruturada e do genograma se deu através da construção de categorias de análises qualitativas, que evidenciaram tanto as regularidades presentes na narrativa dos entrevistados, como seus aspectos diferenciais.

\section{Surgimento e evolução da conduta adicta}

Nessa categoria se descreve o ciclo de vida individual e familiar e os comportamentos facilitadores que contribuíram para o início do uso e abuso de substâncias psicoativas, bem como os aspectos evolutivos da adição da droga.

Observou-se que o momento no qual a droga passou a existir no sistema familiar estava interligado ao próprio ciclo de vida do indivíduo e da família, ou seja, tratava-se de uma fase de transição da família de filhos pequenos para filhos adolescentes, cujo período era caracterizado pelas 
mudanças estruturais dos papéis, seja dos pais e/ ou dosfilhos, o queficademonstrado com o depoimento de uma das mães:

[...] Porque nessa época eu só voltava para casa uma vez por semana, então ele ficava com a irmã. E u sei que acabei ficando muito tempo longe dele ... faltou autoridade minha porque eu fiquei muito longe. (Mãe do PI D g.). ${ }^{1}$

Nessa fase, ocorriam não só as mudanças no aspecto físico dos filhos, como também a transição psicológica da infância para a vida adulta. Associado a isso, e na perspectiva de Carter e McG oldrick (2001); Cerveny (1997); Costa (2003); observou-se também uma redefinição nas funções dos pais quanto às demandas que a fase da adolescência exige, bem como, a família também passa por uma transição no que diz respeito à própria fase adolescente do ciclo de vida familiar, que se entrecruzam com a adolescência do filho. Nesse sentido, a falta de diferenciação dos papéis e a falta de habilidade na transmissão efetiva das regras podem acarretar um desequilíbrio e desafios às regras hierárquicas da família.

Nesse estudo mostrou-se que a droga foi inserida no contexto familiar na pré-adolescência, associada às seguintes características: pertencer ao grupo, pressões dos grupos de pares, rompimentos dos vínculos familiares, pobreza ou ausência do monitoramento parental, aspectos migratórios, tanto de habitação como mudanças escolares, abandono escolar e rigidez nas regras familiares. Conforme o depoimento:

[...] foi na adolescência assim, eu tinha 13 pra 14 anos. $\mathrm{N}$ a verdade foi quando nós nos mudamos lá para 0 C hampagnat. Tinha uma moçada lá, e daí meio quefoi a maneira que eu achei demeaprox imar, e nessa época eu era bem ingênuo, não sabia nada e eles já usavam um monte de coisas. (PI Oj).

Esses dados vão ao encontro das afirmações de Brasil (2004); Kalina (1999); e Silva (2001); no sentido de que fica evidente que na origem do problema drogadictivo concorrem dois fenômenos importantes: a história do indivíduo e a crise que o contexto sócio-familiar, no qual ele vive, está atravessando.
Assim, em termos de dinâmica familiar observou-se que o ciclo vital individual está interconectado com o ciclo vital da família, ou seja, a fase de transição da infância para a adolescência coincide com a fase adolescente da família, que se caracteriza pela presença de aspectos adaptativos e de preocupação ocasionados pelas transições, mudanças de emprego, de local de moradia, dentre outros, provocando uma permissividade ou rigidez nas regras familiares, abrindo um espaço de vulnerabilidade para a entrada da droga.

\section{Mantenedores do comportamento adicto}

Essacategoriareuniu as atitudesindividuais e familiares que contribuíram para a manutenção da conduta adicta no sistema, ou seja, quais eram as regras que governavam o funcionamento dessas famílias. Retrata, principalmente, o mecanismo de negação desencadeado pelo encobertamento da atitude adicta dos familiares e do sistema social, pela distorção do significado da droga dentro e fora do contexto familiar, e 0 aspecto de minimização da conduta adicta.

Isso ficou evidente nos seguintes depoimentos:

[...] E u omitia mesmo, mas era porque era muito sofrido, eu não queria queelas sofressem, queria poupálos. (Mãe do PI Oj.).

[...] E la não fala nada pra gente...A mãe sempre escondeu tudoda gente, nunca falava as wisasreladionadas ao 0j...A minha mãe sempre quis tapar 0 sol com a peneira. (Irmã do PI Oj.).

Observou-se a predominância do sentimento de negação, vergonha, presença da mentira e da cumplicidade entre alguns membros, instaurando-se assim um clima de segredo. A regra era não falar sobre a dro ga enegar o problema na família, como uma forma de proteger o membro adicto e a própria família.

A sso ciado a isso, constatou-se 0 empobrecimento na relação pais efilhos, em termos de comunicação, sustentado de certa maneira a negligências parentais no sentido da omissão de uma conduta que acolhesse a temática sob outra perspectiva. D e certo modo, os pais estavam presos

\footnotetext{
1 Para destacar as falas dos participantes da pesquisa eles serão identificados segundo o grau de parentesco com o paciente identificado, aqui abreviado como PI, seguido da abreviatura do nome do paciente.
} 
numa armadilha, constituída pela omissão e pela presença do modelo adicto dos próprios pais. Isso, em seu conjunto, constituiu um ambiente familiar que influenciou no comportamento adicto dos indivíduos estudados, que ficou evidente na seguinte comunicação de um membro adicto:

[...] $\mathrm{N}$ a minha família cada um fica no seu canto, ninguém seenvolvemuitona vida dos outros...atéporque eles todosbebem, então comoéquevão falar alguma coisa pra mim sejá fazem ooisa errada. E ntão eles não falam nada. (PI Ml.).

Indo ao encontro disso, temos autores como Bepko e Krestan (2001), e Stanton e Todd (1985) que, em suas pesquisas, encontraram alta correlação entre o consumo de drogas no filho e ingestão de álcool pelo pai. Relatam, ainda, que os pais do dependente têm grande apego por jogos de azar e televisão. Nesse estudo ficou visível a relação entre a adição pelo modelo parental e 0 consumo de drogas pelos filhos. O utros elementos deanálise encontrados, que se somam à sustentação do item anterior, referem-se ao fato dos membros adictos coabitarem, mesmo depois de casados, na mesma residência dos pais, ou no mesmo terreno, ou na mesma quadra, mostrando assim uma aglutinação, sendo que tal fato confirma a dificuldade de diferenciação dos modelos parentais.

\section{A família e os diferentes subsistemas impactados com o comportamento adicto a algum de seus membros}

Aqui evidenciamos como cada subsistema reagia diante da descoberta do uso da droga no sistema familiar. Os dados confirmaram que havia uma questão de gênero no aspecto do cuidar, ou seja, como em outras doenças, as mulheres eram as mais envolvidas com 0 adicto e o tratamento deste, tornando-se cuidadoras emocionais superresponsáveis nas famílias.

[...] não sabia como œontar pra minha mãe, ela ia ficar arrasada. E realmente, quando eu contei, ela não aœitou, ficou doente, foi 0 fim pra ela [...]. A atenção évoltada muito para ele, eu acredito que seja por causa do pai dele. A minha mãeamava muito o pai dele, daí, por isso, édiferente o tratamento, elerecebeuma atenção especial, ele foi o único a quem nunca faltou nada, ele tinha de tudo. (Irmã do PI Al.).
Nas famílias estudadas evidenciou-se ainda a presençamaciçadafigurafeminina(mãe,irmã, cunhada) no tratamento. Estas sinalizavam estresses no sistema familiar causado por conflitos, intensas brigas, baixa tolerância e adaptação em função da droga.

Bursztein e Stempliuk (1999) apontam em seus trabalhos, que são frequentes as relações parentalizadas entre um dos progenitores e filho do sexo oposto. O stemas dealiançaeapego encontrados nesse trabalho vão ao encontro, tambem, dos estudos de Stanton e Todd (1985), que ressaltam as alianças entre os membros da família e, dentro dos sistemas familiares, por exemplo, a mãe e 0 filho, irmãs, demonstrando o apego excessivo que existe nessas relações, o qual era, com frequência, muito explícito nas famílias de adictos. Esse dado também foi encontrado na análise dos genogramas.

\section{O rganização relacional da família adicta}

Essa categoria engloba o relacionamento interacional dos membros da família, detalhando 0 funcionamento antes e depois da entrada da substância psicoativa. Evidenciou-se as lembranças positivas e negativas nas relações familiares, a regulação das relações e dos afetos e a inclusão e exclusão dos membros no sistema familiar:

Os depoimentos em continuação exemplificam essas questões:

[...] E u atélembro dele assim pequeno, no meu colo, mas depois de um tempo nunca mais convivemos. (Irmã do PI Oj.).

[...] A minha família desandou deuma vez, não éuma família unida. Q uando a gente se reunia era pra beber e brigar. (PI Ml.).

Observou-se, também, a forma de convivência, tanto afetiva como geográfica; mitos familiares; sentimentos individuais e familiares; perdas materiais e afetivas; medo de mudanças ou desesperança de quenão hajamaisjeito; descréditos e ambiguidades nas atitudes; crenças religiosas.

[...] A bala a família em tudo. A gente não fica mais sossegado, perde a confiança. Pior que foi tudo junto, a droga e a prisão. E le tem um compromisso com a lei. (Pai do PI R.).

[...] T evemuita mudanca, porquea gentetem um sonho, um projeto devida, de trabalho, quer estudar néeagora tá aí né. $V$ ocêvê, eu não saí nem do $1^{\circ}$ ano do $2^{\circ}$ grau. $\mathrm{E}$ u perdi muitas ooisas, coisas materiais. (PI D g.). 
A correlação entre a dor familiar e a responsabilidade do adicto; as condutas antissociais; a desestruturação familiar; a alienação dentro do sistema familiar; a baixa coesão e auto estima familiar foram aspectos que se evidenciaram em todas as famílias pesquisadas.

0 processo de fragilização dos laços familiares, antes e depois da descoberta da droga, fica bem exemplificado no depoimento a seguir:

[...] A ntes de eu usar drogas a família era mais unida, depois queeu passei a usar, a família sedestruiu. Sóque o meu padrasto eu já não me dava com ele, mas depois fioou pior. (PI Al.).

Cabe aqui apontar Minuchin (1982), para o qual os sintomas são provenientes de estresse que excede à capacidade do indivíduo de lidar com ele. No caso da droga, enquanto sintoma, pode servir como um mantenedor homeostático desse sistema, como uma forma simples de camuflar um outro problema da família e manter a mesma estrutura, ou seja, rígida e/ ou suficientemente adequada para sustentar uma conduta adita. Indo ao encontro disso, observou-se nos genogramas a existência de um conflito constante no casal parental e nas uniões das gerações dos filhos, havendo dificuldade em manter as estruturas familiares funcionando, desencadeando várias separações, divórcios e inúmeras reconstituições familiares.

\section{Abordagens das famílias para a solução do problema da adição}

Nessa categoria verificou-se cumplicidade pelo subsistema maternal com o membro adicto para protegê-lo e, por outro lado, o subsistema fraternal denunciava o problema, instaurando um clima de desentendimento entre os membros da família. Cabe aqui lembrar Watzlawick (1967) quando afirma que a mudança autêntica exige a saída do círculo vicioso e a criação de um outro jogo, ou seja, para mudar uma situação estabilizada e infeliz faz-se necessária à modificação de alguns comportamentos que ainda são governados pelas mesmas regras.

Detectou-se que a busca do tratamento se dava quando o membro adicto se sentia pressionado pelo meio externo, como, por exemplo, quando ameaçado de ser preso, em situações de agressões na rua, em momentos de pressões familiares ou ainda quando se encontrava em situação de autodestruição.
Como demonstra o depoimento a seguir: [...] E le tava se destruindo, ele já estava sendo agredido na rua, sendo ameaçado (Irmã do PI A l).

Pôde-se verificar que a conscientização da problemática deu-se após a ocorrência dos aspectos acimadescritos, emborademonstrassem quesomente 0 adicto necessitava de tratamento e que este deveria ter uma solução imediata para um problema que era vivido há muitos anos. Os recursos buscados por essas famílias para a solução do problema, baseavamse no internamento hospitalar ou em chácaras administradas por instituições religiosas, em crenças religiosas ou em outros recursos especializados na área. Como o depoimento:

[...] H oje as coisas estão bem, entre aspas. Q uando ele está den trodecasa tudo está bem. E leestá indona Igreja U niversal. T odos nós estamos, na verdade. $N$ ão quenós sejamos evangélioos, ainda estamos esoolhendo. A gente vai mais porque precisa escutar uma palavra positiva. Faz bem. (Irmã do PI Al.).

Para compreender os ilimitados modelos de tratamento; Figlie, Ribeiro, e Laranjeira (2004), informam que há ambientes de tratamento mais famosos, tradicionais e conhecidos do grande público. Cada um possui vantagens e desvantagens na prestação de auxílio ao dependente químico. Não há serviços melhores do que os outros e sim pacientes mais indicados para cada serviço. Dependendo do momento de cada usuário, um serviço é mais indicado do que o outro.

\section{Padrões familiares adictos ao longo das gerações}

Aqui, descrevem-se os padrões repetitivos da atitude adicta em três gerações: dos avós, dos pais e dos filhos e suas consequências. Os relatos apresentaram, além do uso desubstâncias psicoativas, estados depressivos, suicídios, transtornos mentais e neurológicos, consumo de psicotrópicos, doenças somáticas como infarto, câncer, cirrose, levando, em alguns casos, a óbitos. Essas sequências de eventos mostravam a lealdade ao padrão adicto intergeracionalmente, ou seja, a adição é transmitida de geração em geração, através de rituais, crenças, regras que regulam as atitudes e interações familiares:

[...] E u sei também que o pai do meu pai bebia. [...] $\mathrm{N}$ ão, meu avô morreu de cânœer de esôfago, ele bebia e 
fumava. A minha avó também bebeu durante alguns anos, pelo menos eu via ela bebendo quando a gente morou lá. E la bebia e fumava. (Irmã do PI Al.).

O estudo de Bepko e Krestan (2001), em relação ao alcoolismo, vem confirmar os dados obtidos nessa pesquisa de que a presença do alcoolismo e outras drogas, em qualquer geração, retratam que as fronteiras familiares são rígidas ou difusas demais. E também nos casos avançados, cujas famílias estão organizadas por um longo período em torno da droga, prevalecem 0 rompimento e isolamento em relação à família ampliada e à comunidade.

Durante a construção dos genogramas e das configurações familiares, foi possível mapear lembranças dos comportamentos vividos pelas três gerações, como: abandono, agressões físicas everbais, conflitos parentais, conjugais e fraternais, superfuncionamento das figuras femininas, figura paterna periférica, separações, reconstituições familiares, métodos disciplinaresrígidos. É importante aqui apontar que no momento da construção do genograma, a cada etapa de descoberta de como funcionavam as relações dentro do sistema, as famílias passavam a compreender as repetições dos padrões, especificamente, as atitudes adictas.

Foi observada uma cronificação das atitudes adictas, podendo estas estarem relacionadas à manutenção da identidade familiar em torno das drogas. 0 exemplo disso eram os rituais dessas famílias expressos nos eventos festivos, onde a bebida era o elemento central dos encontros. Geralmente, foi dessa forma que cada geração cresceu no contexto familiar, social e cultural, onde a bebida e outras drogas eram parte natural de suas vidas. Como se verificou, os filhos podem permanecer paralisados nesse ambiente, repetindo o padrão adicto e, sem muito pensar, se unem e/ ou separam de pessoas com comportamentos igualmente adictos.

Também se percebeu a presença de mitos familiares que justificavam a presença da temática da conduta adicta como uma questão "do destino", "é uma coisa feita", afetando diretamente a busca de ajuda, evidenciando desesperança na solução do problema. Outro aspecto que evidenciava a paralisação da família era a presença forte de alguma crença religiosa na família, principalmente no sistema parental, acreditando que a religião seria uma fonte de salvação.
Como resultado dessa categoria, confirmase que 0 fenômeno da adição pode se repetir em várias gerações, constituindo-se de certa forma uma conduta apreendida, influenciando fortemente as pessoas envolvidas pela convivência.

\section{CONCLUSÕES}

Conforme a análise dos dados desse estudo confirma-se que as famílias aparecem como "coautoras", tanto do surgimento do abuso da droga e daevolução como nabuscaderecursos paratratamento dos membros. As famílias participantes dessa pesquisa revelaram casos de adição entre membros na geração atual, assim como nas gerações anteriores, desenhando assim, a intergeracionalidade da atitude adicta, ou seja, a repetição da dinâmica adicta ao longo da história familiar, reafirmando, portanto, que 0 aprendizado ao uso da droga costuma acontecer no seio da família, imitando o modelo adictivo.

Evidenciou-se que a incidência de uso, abuso e dependência química é maior na família da figura materna, o que configura um dado novo, não encontrado na literatura pesquisada dessa temática. Constatou-se, ainda, que os filhos usavam o mesmo tipo de substância que os pais, como, por exemplo, álcool, ou escolhiam outro tipo dedrogadaconsumida pelos pais, mantendo desta forma a conduta adicta.

Constatou-se que a droga pode trazer, na fase da adolescência, consequências sociais, escolares e de conduta tais como: agressividade, falta de motivação para o estudo, falta de respeito às regras e valores, afastamento do convívio familiar e social, conduta antissocial, como, por exemplo, o roubo como uma forma de obter droga. Embora não se possa deixar de considerar que tais condutas também são características presentes no desenvolvimento normal da adolescência, verificou-sequeno ambiente familiar, independentemente do estágio do ciclo vital em que se encontravam, havia elevado índice de alcoolização eintoxicação por outras drogas, além de constantes brigas, agressões entre os membros e existência de distúrbios mentais.

Vários estudos citados ao longo deste trabalho confirmam que os indivíduos que crescem nesse ambiente vivenciam intensas contradições como a falta de aproximação versus excesso de apego; rigidez disciplinar versus permissividade, dificultando, assim, definições claras das regras do sistema familiar. Nesses casos, a droga serve como 
uma maneira do membro adicto diferenciar-se de sua família de origem, mas de um modo frágil, devido ao empobrecimento das regras edos limites.

\section{CONSIDERAÇ̃̃ES FINAIS}

Além dos aspectos referidos, este trabalho vem também enriquecer o espaço científico no que se refere à utilização do genograma, não só como uma técnica clínica de diagnóstico e intervenção, mas como um instrumento de pesquisa eficaz que representaafamílianumadimensão histórica através de sua reativação por três gerações. O s participantes desse estudo, além de mapear sua família nuclear, fizeram o mesmo com suas famílias de origem, abrangendo to das as relações intra e extra familiares, assim como as relações entre as gerações presente e passadas. A visão mais completa dessa rede possibilitou uma leitura integradora dos dados desse estudo, sendo indicado como um instrumento eficaz para a produção de novas pesquisas em que a família seja a protagonista principal.

Diante dos resultados desse estudo, percebe-se a importância de investimento em programas de orientação e tratamento do membro adicto e seus familiares em diferentes abordagens e em diferentes estágios da adição. A temática da dependência química deve ser necessariamente abordada sob a perspectiva da integralidade e complexidade dos diferentes aspectos que nela convergem, para assim poder compreender 0 funcionamentos dessas famílias.

$\mathrm{E}$, finalmente, os resultados do referido estudo ea prática clínica confirmam aimpossibilidade de tratar somente 0 indivíduo adicto, sem incluir 0 sistema familiar no tratamento, de forma que todos os membros da família são, na realidade, vítimas de um jogo infindo, onde a presença da droga só irá perpetuar seus efeitos e consequências.

\section{REFERÊ NCIAS}

Bepko, C., \& Krestan, J. A. (2001). Problema de alcoolismo e 0 ciclo de vida familiar. In As mudanças do ciclo da vida familiar (2a ed.). Porto Alegre: Artes Médicas.

Brasil, V. R. (2004). A recuperação da pessoa do dependente químico: o impacto no seu processo de mudança na família. In Família e Comunidade, 1(1), 93-104.
Bursztein, P. A., \& Stempliuk, V. A. (1999). A cocaína e a família. In C. M. Leite, A. G. Guerra. Cocaína e crack: Dos fundamentos ao tratamento. Porto Alegre: Artmed.

Carter, B., \& Mcgoldrick, M. (O rg.). (2001). As mudanças do ciclo da vida familiar $(2 \mathrm{a}$ ed.). Porto Alegre: Artes Médicas.

Cerveny, C. M. de O. (1997). Família e ciclo vital: N ossa realidade em Pesquisa. São Paulo: Casa do Psicólogo.

Costa, L. F., \& Pereira, L. G. (2003). A perspectiva transgeracional na drogadição. Revista de Psicologia, 21(1/2), 80-88.

Figlie, N. B., \& Moraes, E. (2004). Abuso de álcool, tabaco e outras drogas na adolescência. In N. B. Figlie, S. Bordin, R. Laranjeira. Aconselhamento em Dependência Q uímica. São Paulo: Roca.

Figlie, N. B., Ribeiro, M., \& Laranjeira, R. (2004). O rganização de serviços de tratamento para a dependência química. In N. B. Figlie, S. Bordin, R. Laranjeira. Aconselhamento em dependência química. São Paulo: Roca.

Freitas, L. (2002). Adolescência, família e drogas: A função paterna e a questão de limites. Rio de Janeiro: Mauad.

Galanter, M., \& Brook D. (2001). Network therapy for addiction: bringing family and peer support into office practice. Int J Group Psychother, 51, 101-22.

Gerson, R., \& McGoldrick, M. S. W. (2001). G enetogramas e o Ciclo de vida Familiar. In Carter, B. \& M. Mcgoldrick. (O rg.). As mudanças do ciclo da vida familiar (2a ed.). Porto Alegre: Artmed.

Kalina, E. (1999). Drogadição hoje: Indivíduo, família e sociedade. São Paulo: Artes Médicas Sul.

Kaufmann, E. F. (1989). Family therapy in substance abuse treatment (psychoactive substance use disorders - not alcoholic). In Treatment of Psychiatric D isorders: A Task Force, American Psychiatric Association. Washington: p. 1397-1416.

Minuchin, S. (1982). Família, funcionamento e tratamento. Porto Alegre: Artes Médicas. 
Minuchin, P., Colantino, J., \& Minuchin, S. (1999). Trabalhando com famílias pobres. Porto Alegre: Artes Médicas Sul.

Rezende, M. M. (1997). Curto-circuito familiar e drogas: Análise de relações familiares e suas implicações na farmacodependência $(2 \mathrm{a}$ ed.). Taubaté: Cabral Editora Universitária.

Silva, E. A. (2001). A bordagens familiares. Jornal Brasileiro de Dependência Química ABAD, 2(1), 21-24.

Stanton, M. D., \& Todd, T. C. (1985). Terapia familiar del abuso y adicción a las drogas. Barcelona: G edisa.

Sudbrack, M. F. O. (2004). Terapia familiar sistêmica. In D. S. Seibel, A. Toscano Jr. Dependência de drogas. São Paulo: Ateneu.

Watzlawick, P., Beavin, J., \& Jackson, D. D. (1967). Pragmática da comunicação humana. São Paulo: Pultnix.

Recebido: 26/ 09/ 2007

Received: 09/26/ 2007

Aprovado: $19 / 08 / 2008$

A pproved: 08/ 19/ 2008 